\title{
Using Weather Variables Pre- and Post-heading to Predict Deoxynivalenol Content in Winter Wheat
}

\author{
D. C. Hooker, A. W. Schaafsma, and L. Tamburic-Ilincic, Ridgetown College, University of Guelph, Guelph, \\ Ontario, Canada, NOP 2C0
}

\begin{abstract}
Hooker, D. C., Schaafsma, A. W., and Tamburic-Ilincic, L. 2002. Using weather variables preand post-heading to predict deoxynivalenol content in winter wheat. Plant Dis. 86:611-619.

Substantial economic losses have occurred because of unacceptable concentrations of deoxynivalenol (DON) in wheat. Accurate predictions of DON in mature grain at wheat heading are needed to make decisions on whether a control strategy is needed. Our objective was to identify important weather variables, and their timing, for predicting concentrations of DON in mature grain at wheat heading. We measured the concentration of DON in 399 farm fields in southern Ontario, Canada, from 1996 to 2000. DON varied in field samples from undetectable to over 29 $\mu \mathrm{g} \mathrm{g}^{-1}$. Weather variables, such as daily rainfall, daily minimum and maximum air temperatures, and hourly relative humidity, were estimated for each field from nearby weather stations and were normalized to the date of $50 \%$ head emergence. Stepwise multiple regression procedures determined the most important weather variables and their timing around heading. DON was responsive to weather in three critical periods around heading. In the first period, 4 to 7 days before heading, DON generally increased with the number of days with $>5 \mathrm{~mm}$ of rain and decreased with the number of days of $<10^{\circ} \mathrm{C}$. In the second period, 3 to 6 days after heading, DON increased with the number of days of rain $>3 \mathrm{~mm}$ and decreased with days exceeding $32^{\circ} \mathrm{C}$. In the third period, 7 to 10 days after heading, DON increased with number of days with $>3 \mathrm{~mm}$ of rain. A relationship between relative humidity and DON was not detected. Overall, $73 \%$ of the variation in the concentration of DON was explained by using weather from all three critical periods. Concentrations of DON $<2.0 \mu \mathrm{g} \mathrm{g}{ }^{-1}$ were predicted best; in fact, concentrations of DON of $<1.0 \mu \mathrm{g} \mathrm{g}^{-1}$ were predicted correctly on over $89 \%$ of the fields used to train the model.
\end{abstract}

Additional keywords: Fusarium head blight, scab

Substantial economic losses of wheat (Triticum aestivum L. em. Thell) have occurred in Ontario because of periodic epidemics of Fusarium head blight (FHB) or scab. The most prevalent causal organism of FHB in Ontario is Fusarium graminearum Schwabe, which produces the mycotoxin deoxynivalenol (DON); the toxin is produced as the disease progresses during the growing season. The cost of an epidemic in 1996 was estimated to exceed over $\$ 100$ million (CDN) in Ontario (J. Whitelaw, Ontario Wheat Producers Marketing Board, personal communication). The frequency of the problem and its severity appear to be increasing in recent years. Unacceptable concentrations of DON in wheat have exceeded $1 \mu \mathrm{g} \mathrm{g}^{-1}$ in scattered, localized areas across the province in every year from 1997 to 2000 (unpublished survey data). Another $\$ 25$ million (CDN) was lost in 2000 because of Fusarium-damaged grain and unacceptable

Corresponding author: A. W. Schaafsma E-mail: aschaafsma@ridgetownc.uoguelph.on.ca

Accepted for publication 25 January 2002.

Publication no. D-2002-0326-01R

(C) 2002 The American Phytopathological Society concentrations of DON (J. Whitelaw, Ontario Wheat Producers Marketing Board, personal communication).

Concentrations of DON $<1.0 \mu \mathrm{g} \mathrm{g}^{-1}$ are permitted in wheat destined for human consumption, and up to $5 \mu \mathrm{g} \mathrm{g}^{-1}$ for livestock feed (18). Wheat grain with DON concentrations of over $5 \mu \mathrm{g} \mathrm{g}^{-1}$ may not be marketable (30). Visual incidence or severity of FHB is usually reported in the literature as an indicator of yield and test weight because the assessment is quick and inexpensive (8). However, in Ontario, winter wheat is frequently contaminated by at least $1.0 \mu \mathrm{g} \mathrm{g} \mathrm{g}^{-1}$ of DON (26). Because DON can form in the absence of observable disease symptoms $(13,17)$, the actual measurement of DON is preferred when investigating the factors responsible for DON production.

FHB epidemics are usually associated with an abundance of inoculum and favorable weather conditions around wheat heading $(14,22)$. Substrates for the production of inoculum are not limiting in the Great Lakes basin, especially with the adoption of reduced tillage practices that retain corn and wheat residues on the soil surface (31). Optimal conditions for the formation and maturity of the inoculum have been reported when the substrate is moist (13) and with temperatures between
20 and $30^{\circ} \mathrm{C}$ (10). Low inoculum levels usually occur in dry periods (14). Regardless of the level of inoculum available, favorable weather conditions are critical for infection to occur in wheat heads. Only a small amount of inoculum may be needed to cause concern for high concentrations of DON if weather conditions are favorable for infection (19).

Susceptibility to infection has been reported to be the greatest from flowering to the early dough stage, or Zadoks growth stages 60 to 83 (24). Infection is mainly dependent on the combination of rainfall, the duration of canopy wetness, and temperature conditions relative to the stage of wheat development. Pugh et al. (24) found that wheat heads exposed to $F$. graminearum at $25^{\circ} \mathrm{C}$ for $36 \mathrm{~h}$ of continuous wetness were $18 \%$ infected, compared with $77 \%$ infected at $48 \mathrm{~h}$ of continuous wetness. Another study found minimal infection with a duration of wetness of less than $24 \mathrm{~h}$ (17). Temperatures of 30 to $32^{\circ} \mathrm{C}$ tend to reduce infection and fungal growth (25). Lacey et al. (17) reported reduced infection with temperatures of less than $9^{\circ} \mathrm{C}$ and greater than $26^{\circ} \mathrm{C}$. Most of these studies have been conducted under controlled conditions in the growth room.

Little has been reported on specific environmental conditions in farm fields responsible for elevated concentrations of DON. Important weather variables and their timing for spore release and infection need to be further examined for predicting concentrations of DON in mature wheat grain. The impact of various environments has typically been assessed through simple effects of one or two variables that can be artificially controlled either in the growth room or in small field plots. As a result, models developed from those investigations are usually site-specific and do not provide acceptable accuracy when applied to diverse and complex environments (5). The potential to predict the level of contamination of grain with DON across diverse environmental conditions may be possible by using weather data from many fields over several years. Other researchers have investigated and published the effects of weather variables on other diseases using natural geospatial and cultural variation on farm fields $(2,4,9,14,15,33)$. If weather variables can be quantified into DON-response relationships, a model could be developed to predict the concentration of DON using both forecasted and actual weather data for specific fields. This 
tool may be useful to investigate the need for fungicide applications to reduce the potential for unacceptable concentrations of DON. Objectives of this work were: (i) to identify critical weather parameters and time periods around wheat heading that promote the occurrence and accumulation of DON, and (ii) to develop a model that predicts concentrations of DON using weather data around wheat heading.

\section{MATERIALS AND METHODS}

From 1996 to 2000, 399 farm winter wheat fields were selected at random just before harvest across southern and eastern Ontario. The study involved 83 farm fields in 1996, 72 in 1997, 73 in 1998, 101 in 1999, and 70 in 2000. Agronomic practices used in each field were not known prior to selection.

Hand shears were used to harvest mature wheat spikelets at Zadoks 92 (34) from 10, $2-\mathrm{m}^{2}$ areas equally spaced across the center of each field. Spikelets were threshed with a stationary plot thresher, which was adjusted to retain any light or shriveled kernels. The entire grain sample was finely ground through a ROMER mill (Model 2A, Romer Labs, Inc., Union, MO). In 1996, DON was extracted from a 1-g subsample in a 5-ml mixture of methanol and water (1:9), and quantified using competitive direct enzyme-linked immunosorbent assay (CD-ELISA) (27). The same procedures were used from 1997 to 2000, except that DON was extracted from a $20-\mathrm{g}$ subsample in $100 \mathrm{ml}$ of methanol and water (1:9), and quantified with the commercially prepared EZ-Quant DON Plate Kit (Beacon Analytical Systems, Inc., Scarborough, ME). Both analytical procedures can detect DON to the lower limit of 0.2 $\mu \mathrm{g} \mathrm{g}^{-1}$.

The date of wheat head emergence was estimated for each field by assuming it corresponded to the heading date of the same variety planted at the nearest site of the multilocation network of Ontario Cereal Tests (12). Cereal test sites were within $30 \mathrm{~km}$ of each field in the survey. The date of wheat head emergence was defined when the heads of $50 \%$ of the plants fully emerged from the boot, or Zadoks 59 (34).

Daily weather data were normalized for each field with the date of wheat head emergence. Daily rainfall, daily minimum and maximum air temperatures, and hourly relative humidity $(\mathrm{RH})$ were estimated for each field for a 48-day period centered around head emergence. These weather data were obtained from the nearest Environment Canada weather station that was within $20 \mathrm{~km}$ of each field location. Daily binary values were calculated for each of four weather variables (i.e., $0=$ does not match weather criterion for the day, $1=$ matches criterion): (i) when daily rainfall $>5 \mathrm{~mm}$ (before heading) or $3 \mathrm{~mm}$ (after heading), (ii) when minimum temperature was $<10^{\circ} \mathrm{C}$, (iii) when maximum temperature was $>32^{\circ} \mathrm{C}$, and (iv) when $\mathrm{RH}$ was $>90 \%$ at noon. Different criteria were chosen for rainfall before and after heading because rainfall exceeding $5 \mathrm{~mm}$ has been regarded as important for perithecial formation (23), while $3 \mathrm{~mm}$ was presumed to be substantial to wet the wheat canopy for infection. Daily binary values (i.e., 0 or 1 ) for each weather variable were then summed in simple 4-day moving periods or "windows" in the following equation,

$$
W V_{i}=\sum_{i=1}^{45} \sum_{d=1}^{4} B_{(d+i-1)}
$$

where $B_{(d+i-1)}$ is the binary value (i.e., 0 or 1) within the 4-day interval $i$ on day $d$ relative to the day of head emergence $(d=$ $0)$. Therefore, an array of 45 summed values was calculated for each weather variable, starting at interval $i=1$ for the period between 24 and 21 days before heading, and ending with interval $i=45$ or between 20 and 23 days after heading. The summed values represent up to five levels of intensity for each weather variable within a 4day period, from 0 (i.e., no days matching criteria) to 4 (i.e., all days matching criteria). Stepwise regression procedures (SAS Institute, Cary, NC) identified the most important weather variables for accumulation of DON, and their timing relative to heading, by regressing the summed values on the concentration of DON for each field in every year of the survey. The analysis ensured that observations from all fields and years were independent of each other (O. B. Allen, Ashton Statistical Consulting, University of Guelph, Guelph, Ontario, Canada, personal communication). Prior to analysis, concentrations of DON were transformed by $\ln (x+0.1)$ to satisfy assumptions of normality.

Final models derived from multiple regression were chosen based on several criteria. One criterion was the largest multiple coefficient of determination $\left(R^{2}\right)$. Because the $R^{2}$ value should not be used as a sole indicator of the ability of a model to describe, predict, and control the dependent variable (6), four additional criteria were used. First, for each successive independent variable added to a model, the $R^{2}$ would increase; however, the independent variable may only be useful if the standard error $(s)$ of the prediction decreases. Second, Mallow's $C$ statistic was used to identify models that were not biased; a $C$ statistic close to the number of parameters in the model is desirable (6). Third, the predicted error sum of squares (PRESS) statistic compared the predictive ability of models. A low PRESS, for example, indicates better predictive ability compared with another model with a higher PRESS statistic (6). Fourth, the variance inflation factor (VIF) indicated multicollinearity among other "independent" variables in the model; a value for an independent variable close to 1.0 is desirable, and a value $>10$ indicates that the variable contributes redundant information (6). Models were further refined by identifying influential observations and suspected outliers by the INFLUENCE statistic (SAS). A more detailed description on using these tools for developing appropriate models is described in Bowerman and O'Connell (6).

In 2000, final models were evaluated on 17 farm fields located within $2 \mathrm{~km}$ of one of five Environment Canada weather stations in Ontario. The weather stations were separated by more than $50 \mathrm{~km}$. The fields were selected based on proximity to the weather station, not on variety or other agronomic practices. Methods to obtain DON data for the validation were the same as those used for the development of the model.

\section{RESULTS}

Agronomic practices on surveyed fields. Fields surveyed between 1996 and 2000 represented an array of agronomic practices and winter wheat cultivars. A list of agronomic practices, and the effects on contamination by DON, is presented with greater detail in another paper (26). In summary, the proportion of fields planted to soft red wheat increased from $14 \%$ in 1996 to $51 \%$ in 2000 , while the number of fields planted to soft white wheats declined. Soybean and other bean crops were grown in the year previous to the survey on more than $70 \%$ of wheat fields in the 5year period. Corn or wheat was the previous crop grown on less than $9 \%$ of surveyed wheat fields in any year. More than $76 \%$ of the fields in the survey were cropped to either corn or wheat within 3 years before the survey. Tillage systems, which bury most of the residue from previous years, were used on approximately $30 \%$ of the fields. Minimum or no-tillage, in which at least $20 \%$ of the soil surface was covered with residue following wheat planting, was used to plant wheat on the remaining $70 \%$ of fields.

General weather conditions on fields from 1996 to 2000. For the period 7 days before and 10 days after wheat heading, mean maximum temperatures across all fields were between 21 and $26^{\circ} \mathrm{C}$ in 1996 , 22 and $28^{\circ} \mathrm{C}$ in 1997,18 and $26^{\circ} \mathrm{C}$ in 1998 , 21 and $31^{\circ} \mathrm{C}$ in 1999 , and 18 and $29^{\circ} \mathrm{C}$ in 2000. Mean daily minimum temperatures in the same period across all fields were between 12 and $17^{\circ} \mathrm{C}$ in 1996,12 and $18^{\circ} \mathrm{C}$ in 1997,6 and $13^{\circ} \mathrm{C}$ in 1998,7 and $19^{\circ} \mathrm{C}$ in 1999, and 8 and $15^{\circ} \mathrm{C}$ in 2000 (Fig. 1). In the period between 3 and 6 days after heading (approximately during anthesis), temperatures did not exceed $30^{\circ} \mathrm{C}$ in 1996 and 2000 , but did exceed $30^{\circ} \mathrm{C}$ in $33 \%$ of the fields in $1997,25 \%$ of the fields in 1998 , and 93\% of the fields in 1999 (data not shown).

Rainfall across surveyed fields was greater and more frequent in a period 12 days before and 12 days after heading in 
1996, compared with the same periods for each year from 1997 to 2000 (Fig. 1). In the period from heading to 8 days before heading in 1996, at least 2 days of rain $>5$ $\mathrm{mm}$ occurred on $90 \%$ of fields, compared with $14 \%$ of the fields in $1997,32 \%$ in $1998,52 \%$ in 1999 , and $26 \%$ in 2000 (data not shown). In the period from heading to 10 days after heading, at least 2 days of rain $>3 \mathrm{~mm}$ occurred on $96 \%$ of the fields in 1996, compared with $90 \%$ in $1997,30 \%$ in 1998 , none in 1999 , and $50 \%$ in 2000 .

Concentrations of DON in mature wheat grain from 1996 to 2000 . Concentrations of DON exceeded $1.0 \mu \mathrm{g} \mathrm{g}^{-1}$ in $94 \%$ of
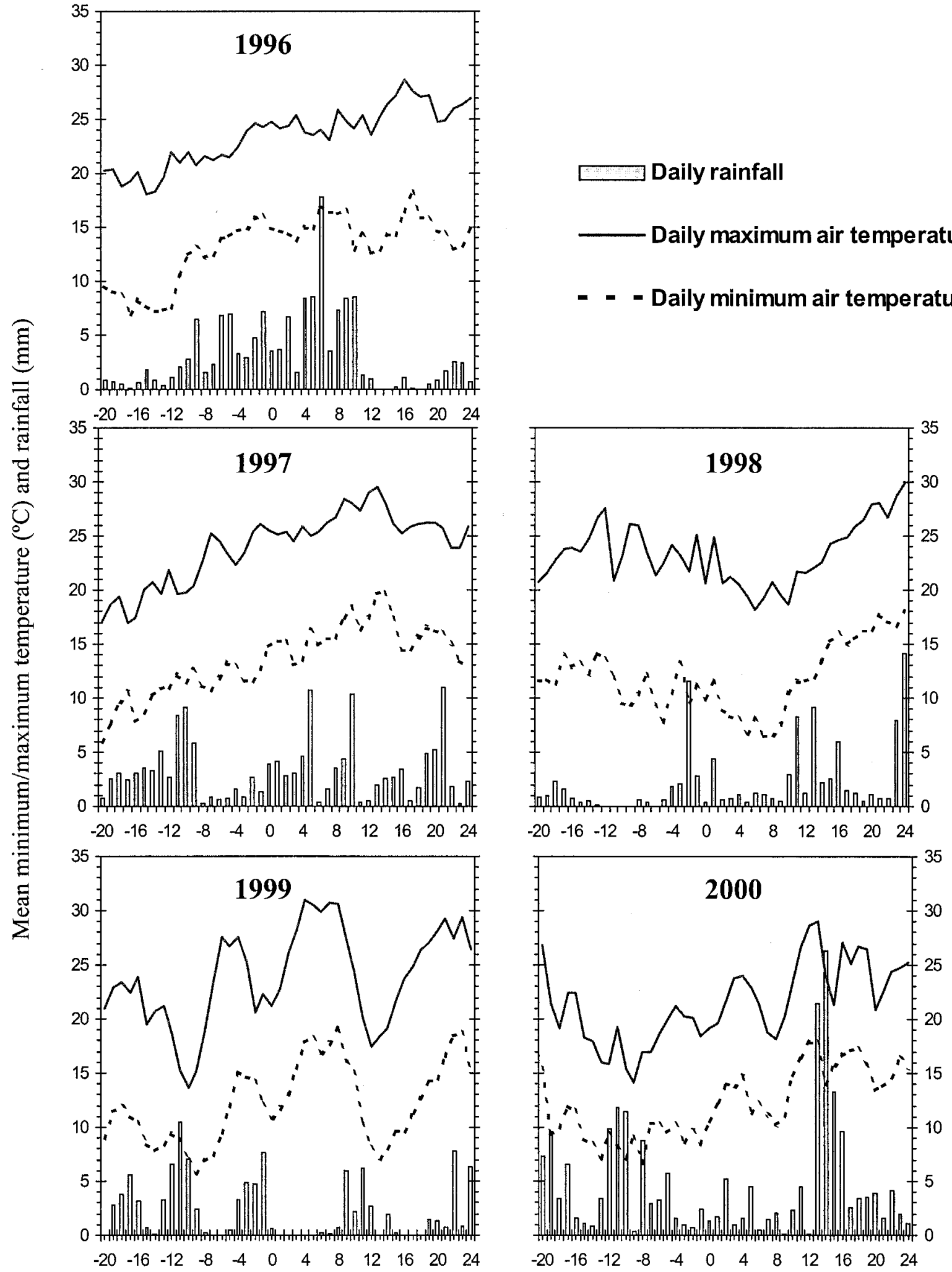

Day relative to wheat heading (0)

Fig. 1. Average rainfall and air temperatures assumed across surveyed field-locations from 20 days before Zadoks 59 or wheat heading ( -20$)$ to 24 days after heading (+24). Data for each field were normalized to $50 \%$ head emergence of the same variety in nearby Cereal Test locations. 
the fields in 1996 and $54 \%$ of the fields in 2000 (Table 1). In contrast, DON was $<1.0$ $\mu \mathrm{g} \mathrm{g}^{-1}$ in at least $59 \%$ of fields in $1997,89 \%$ in 1998, and $76 \%$ in 1999. Six percent of the wheat samples contained DON at $>5 \mu \mathrm{g} \mathrm{g}^{-1}$ in 2000 , compared with $60 \%$ of the fields in 1996. DON exceeded $85 \mu \mathrm{g} \mathrm{g} \mathrm{g}^{-1}$ in three fields in 1996 (data not shown). Cultural not unique in 1996. These data were discarded from the 1996 data set and from Table 1 after statistical analysis identified them outliers and highly influential in the subsequent development of the models.

Critical periods of rainfall around heading. Stepwise multiple regression identified several weather variables and three main periods around heading associated with DON. Both rainfall and temperature were important weather variables for predicting DON $(P<0.05)$. Relative humidity ( $>90 \%$ at noon) was not a factor practices and weather at these fields were

around heading $(P>0.10)$, so this variable was not used in any equation. The weather most influential for predicting DON occurred in three critical periods: (i) 4 to 7 days before heading, (ii) 3 to 6 days after heading, and (iii) 7 to 10 days after heading.

Three equations were developed to predict DON using rainfall and temperature data (Table 2). Equation 1 predicts DON using weather information from 4 to 7 days before heading:

$$
\begin{aligned}
& \text { DON }=\exp [-0.30+1.84 \text { RAINA } \\
& \left.\quad-0.43(\text { RAINA })^{2}-0.56 \text { TMIN }\right]-0.1
\end{aligned}
$$

where DON $=$ concentration of DON $(\mu \mathrm{g}$ $\mathrm{g}^{-1}$ ), RAINA is the number of days of rain $>5 \mathrm{~mm} \mathrm{day}^{-1}$ in the period 4 to 7 days before heading, and TMIN is the number of days of temperatures $<10^{\circ} \mathrm{C}$ between 4 and 7 days before heading.

Two weather variables, the days of rainfall $>5 \mathrm{~mm}$ (linear variable RAINA and

Table 1. Concentrations of deoxynivalenol (DON) in wheat fields studied from 1996 to 2000 across Ontario

\begin{tabular}{lcccrr}
\hline & \multicolumn{5}{c}{ Percentage of fields surveyed in year } \\
\cline { 2 - 6 } Concentration of DON $\left(\boldsymbol{\mu g ~ g}^{-\mathbf{1}}\right)$ & $\mathbf{1 9 9 6}$ & $\mathbf{1 9 9 7}$ & $\mathbf{1 9 9 8}$ & $\mathbf{1 9 9 9}$ & $\mathbf{2 0 0 0}$ \\
\hline$<0.1$ (very low) & 0.0 & 25.0 & 65.8 & 33.7 & 0.0 \\
$0.1-0.9$ (low) & 6.0 & 34.7 & 23.2 & 42.6 & 45.3 \\
$1.0-1.9$ (moderate) & 15.7 & 34.7 & 5.5 & 7.9 & 23.4 \\
$2.0-4.9$ (high) & 18.1 & 5.6 & 5.5 & 13.9 & 25.0 \\
$\geq 5.0$ (very high) & 60.2 & 0.0 & 0.0 & 2.0 & 6.3 \\
Mean DON concentration & 8.0 & 0.8 & 0.3 & 0.9 & 1.6 \\
Minimum DON concentration & 0.1 & 0.0 & 0.0 & 0.0 & 0.2 \\
Maximum DON concentration & 29.2 & 4.1 & 3.8 & 6.2 & 11.5 \\
Number of fields & 83 & 72 & 73 & 101 & 70 \\
\hline
\end{tabular}

quadratic variable RAINA ${ }^{2}$ ) and days with minimum air temperatures $<10^{\circ} \mathrm{C}$ (variable TMIN), explained $55 \%$ of the variability of DON across all fields using weather data only between 4 and 7 days before heading. Rain alone accounted for $41 \%$ of the variability in DON as shown in partial $R^{2}$ analysis (Table 2). When the minimum temperature variable (i.e., variable TMIN) was held constant, partial regression showed a quadratic relationship between the concentration of DON and the number of days of rain $>5 \mathrm{~mm}$ during the 4- to 7day period before heading (i.e., variable RAINA). Predicted concentrations of DON were at a maximum with 2 or 3 days of rain during that period. In contrast with rain, DON decreased with air temperatures below $10^{\circ} \mathrm{C}$ during the period 4 to 7 days before heading. Nevertheless, rain was the most important variable for predicting concentrations of DON.

Equations 2 and 3 predicted DON using weather information from 7 days before heading to 10 days after heading:

when RAINB $>0$, then

$$
\begin{gathered}
\text { DON }=\exp [-2.15+2.21 \text { RAINA }-0.61 \\
(\text { RAINA })^{2}+0.85 \text { RAINB }+0.52 \text { RAINC } \\
-0.30 \text { TMIN }-1.10 \text { TMAX }]-0.1
\end{gathered}
$$

and when $\mathrm{RAINB}=0$, then

$$
\text { DON }=\exp (-0.84+0.78 \text { RAINA }
$$$$
+0.40 \text { RAINC }-0.42 \text { TMIN })-0.1
$$

\begin{tabular}{|c|c|c|c|c|c|c|c|c|}
\hline Equation $^{a}$ & Variable $^{\text {b }}$ & $\begin{array}{l}\text { Parameter } \\
\text { estimate }\end{array}$ & SE & $\begin{array}{c}\text { Parameter esti- } \\
\text { mate } P>|T|\end{array}$ & VIF $^{c}$ & $\begin{array}{c}\text { Partial }^{\mathrm{d}} \\
R^{2}\end{array}$ & $\begin{array}{c}\text { Equation }^{\mathrm{e}} \\
\boldsymbol{R}^{2}\end{array}$ & PRESS $^{c}$ \\
\hline 1 & $\begin{array}{l}\text { Constant } \\
\text { RAINA } \\
\text { TMIN } \\
\text { RAINA }^{2}\end{array}$ & $\begin{array}{r}-0.30 \\
1.84 \\
-0.56 \\
-0.43\end{array}$ & $\begin{array}{l}0.116 \\
0.193 \\
0.053 \\
0.089\end{array}$ & $\begin{array}{l}0.0114 \\
0.0001 \\
0.0001 \\
0.0001\end{array}$ & $\begin{array}{l}7.0 \\
1.1 \\
7.1\end{array}$ & $\begin{array}{l}0.37 \\
0.14 \\
0.04\end{array}$ & 0.55 & 421 \\
\hline 2 & $\begin{array}{c}\text { Constant } \\
\text { RAINA } \\
\text { TMIN } \\
\text { RAINC } \\
\text { RAINA }^{2} \\
\text { RAINB } \\
\text { TMAX }\end{array}$ & $\begin{array}{r}-2.15 \\
2.21 \\
-0.30 \\
0.52 \\
-0.61 \\
0.85 \\
-1.10\end{array}$ & $\begin{array}{l}0.218 \\
0.196 \\
0.059 \\
0.069 \\
0.079 \\
0.102 \\
0.293\end{array}$ & $\begin{array}{l}0.0001 \\
0.0001 \\
0.0001 \\
0.0001 \\
0.0001 \\
0.0001 \\
0.0002\end{array}$ & $\begin{array}{l}\ldots \\
5.9 \\
1.3 \\
1.2 \\
5.5 \\
1.2 \\
1.0\end{array}$ & $\begin{array}{l}0.46 \\
0.10 \\
0.08 \\
0.07 \\
0.06 \\
0.02\end{array}$ & 0.79 & 127 \\
\hline 3 & $\begin{array}{c}\text { Constant } \\
\text { RAINA } \\
\text { TMIN } \\
\text { RAINC }\end{array}$ & $\begin{array}{r}-0.84 \\
0.78 \\
-0.42 \\
0.40\end{array}$ & $\begin{array}{l}0.190 \\
0.092 \\
0.071 \\
0.134\end{array}$ & $\begin{array}{l}0.0001 \\
0.0001 \\
0.0001 \\
0.0030\end{array}$ & $\begin{array}{l}\ldots \\
1.2 \\
1.3 \\
1.4\end{array}$ & $\begin{array}{l}0.40 \\
0.14 \\
0.02\end{array}$ & 0.56 & 155 \\
\hline
\end{tabular}

where DON $=$ concentration of DON $(\mu \mathrm{g}$ $\mathrm{g}^{-1}$ ), RAINA is the number of days of rain $>5 \mathrm{~mm} \mathrm{day}^{-1}$ in the period 4 to 7 days be-

Table 2. Statistics of equations within the model to predict deoxynivalenol using actual or forecasted weather variables before wheat head emergence, with rain 3 to 6 days after heading, or with no rain 3 to 6 days after heading

\footnotetext{
${ }^{a}$ Degrees of freedom of the mean square error term for equations 1, 2, and 3 are 396, 195, and 192, respectively. All equations were significant at $P<$ 0.0001 .

${ }^{\mathrm{b}}$ RAINA $=$ no. days of rain $>5 \mathrm{~mm}$ in the 4-day period from 4 to 7 days prior to wheat head emergence; RAINA ${ }^{2}=$ RAINA squared; RAINB $=$ no. days of rain $>3 \mathrm{~mm}$ in the 4-day period from 3 to 6 days after wheat head emergence; RAINC $=$ no. days of rain $>3 \mathrm{~mm}$ in the 4-day period from 7 to 10 days after wheat head emergence; TMIN $=$ no. days of daily minimum temperature $<10^{\circ} \mathrm{C}$ in the 4-day period before wheat head emergence; TMAX $=$ no. days of daily maximum temperature $>32^{\circ} \mathrm{C}$ in the 4-day period 3 to 6 days after wheat head emergence.

${ }^{\mathrm{c}} \mathrm{VIF}=$ variance inflation factor; PRESS $=$ prediction error sum of squares.

${ }^{\mathrm{d}}$ Partial coefficient of determination $\left(R^{2}\right)$ values of variables added to each model in the order of the stepwise method of model selection.

${ }^{\mathrm{e}} R^{2}=$ overall coefficient of determination of each equation model.
} 
fore heading, RAINB is the number of days of rain $>3 \mathrm{~mm} \mathrm{day}^{-1}$ in the period 3 to 6 days after heading, RAINC is the number of days of rain $>3 \mathrm{~mm} \mathrm{day}^{-1}$ in the period 7 to 10 days after heading, TMIN is the number of days with temperatures $<10^{\circ} \mathrm{C}$ between 4 and 7 days before heading, and TMAX is the number of days with temperatures $>32^{\circ} \mathrm{C}$ between 4 and 7 days before heading. Equation 2 was developed from 193 fields that received at least 1 day of rain $>3 \mathrm{~mm}$ between 3 and 6 days after head emergence, and equation 3 (Table 2) was developed from 206 fields that were dry during the 3 to 6 days after heading.

When rain occurred between 3 and 6 days after heading, equation 2 explained $79 \%$ of the variability in DON (Table 2). Preheading weather data used in equation 1 were also important components in equation 2. Partial $R^{2}$ analysis showed that the preheading days of rainfall $>5 \mathrm{~mm}$ (linear RAINA and quadratic RAINA $^{2}$ ) and minimum temperature $<10^{\circ} \mathrm{C}$ (TMIN) predicted $63 \%$ of the variability in DON, followed by rain between 7 and 10 days after heading (RAINC), then rain $>3 \mathrm{~mm}$ between 3 and 6 days after heading (RAINB), and lastly the days with maximum temperature (TMAX) exceeding $32^{\circ} \mathrm{C}$ between 3 and 6 days after heading (Table 2). Rain variables were usually more important in the equations than temperature variables. Rain variables alone explained approximately 67 of the $79 \%$ variation in DON explained in equation 2. In general, DON increased with more frequent rain during the three periods around heading, and decreased with air temperatures below $10^{\circ} \mathrm{C}$ in the period before heading and with temperatures exceeding $32^{\circ} \mathrm{C}$ between 3 and 6 days after heading.

Concentrations of DON were less predictable in fields with dry weather during the 3- to-6 day period after heading (equation 3). Only $56 \%$ of the variability in DON was explained in equation 3 (Table $2)$. Despite similar $R^{2}$ values for equation 1 and equation 3 (55 and $56 \%$ ), a lower PRESS statistic for equation 3 means that DON is more predictable using this equation compared with equation 1 . Preheading weather data used in equation 1 were also important components in equation 3 , with the exception that the quadratic component of days of $>3 \mathrm{~mm}$ rainfall $\left(\right.$ RAINA $^{2}$ ) was not a significant variable in the model. Partial $R^{2}$ analysis showed that rain $>5 \mathrm{~mm}$ and minimum temperatures $<10^{\circ} \mathrm{C}$ during 4 to 7 days before heading explained 54 of $56 \%$ variability explained by equation 3 , while the occurrence of rain between 7 and 10 days after heading was associated with $2 \%$ of the variability in DON (Table 2).

Most of the values of variance inflation factors (VIF) (i.e., indicator of collinearity) associated with independent variables in the equations were within a desirable range of 1.0 to 1.4 in all three equations. The VIFs for both RAINA and the quadratic variable RAINA ${ }^{2}$ were $>5.5$ (Table 2). All other variables were weakly correlated with one another $(0.17<r<0.39)$ despite statistical significance for all correlations at $P=0.001$ (Table 3). In general, temperature variables were negatively correlated to rain variables. As expected, the concentration of DON was positively correlated with rain during the three periods around heading $(0.57>r>0.40 ; P<0.001)$ and negatively correlated with minimum temperatures below $10^{\circ} \mathrm{C}$ during the period before heading $(r=-0.51 ; P<0.0001)$, and maximum temperatures $>32^{\circ} \mathrm{C}$ during the period just after heading $(r=-0.33 ; P<$ 0.0001) (Table 3).

Model development. A flowchart illustrates the application of the equations using actual or forecasted weather information from 7 days before heading to 10 days after heading (Fig. 2). The flowchart is initiated with wheat stage observations in the field before the emergence of the flag leaf, or approximately 12 days before heading. Once the day of heading is estimated at 12 days or less, data from 5-day weather forecasts may be included in equation 1 (i.e., the fifth day of the forecast is the first day of data input in 4 to 7 days before heading). Calculations of weather data from forecasted weather probabilities will be discussed in a subsequent paper. Equations 2 and 3 may be used for predicting DON when either forecasted or actual weather values become available in the 3- to 10-day period after heading.

Overall, the model predicted $73 \%$ of the variability in concentrations of DON across 399 fields over 5 years (Fig. 3). Predictions were more accurate in fields where actual DON was $<2.0 \mu \mathrm{g} \mathrm{g}^{-1}$ of wheat, or approximately $0.7(\ln x+0.1) \mu \mathrm{g} \mathrm{g}^{-1}$ in Figure 3. For example, the model predicted DON at $<1.0$ $\mu \mathrm{g} \mathrm{g}^{-1}$ on $89 \%$ of the 196 wheat fields containing $<1.0 \mu \mathrm{g} \mathrm{g}^{-1}$ in the survey. Furthermore, concentrations of DON $<2.0 \mu \mathrm{g} \mathrm{g}^{-1}$ were predicted on $74 \%$ of those fields containing $<2.0 \mu \mathrm{g} \mathrm{g}^{-1}$ in the survey; however, DON was predicted to exceed $5.0 \mu \mathrm{g} \mathrm{g}^{-1}$ on only $59 \%$ of 51 wheat samples containing $>5.0 \mu \mathrm{g} \mathrm{g}^{-1}$ (Fig. 3).

Table 3. Pearson correlation coefficients $(r)^{\mathrm{a}}$ among independent variables and deoxynivalenol as selected by stepwise multiple regression procedures using data from all wheat farm fields surveyed across Ontario from 1996 to $2000(n=399)$

\begin{tabular}{lcccccc}
\hline Variable $^{\mathbf{b}}$ & RAINA & RAINA $^{2}$ & RAINB & RAINC & TMIN & TMAX \\
\hline RAINA $^{2}$ & 0.92 & $\ldots$ & $\ldots$ & $\ldots$ & $\ldots$ & $\ldots$ \\
RAINB & 0.17 & 0.18 & $\ldots$ & $\ldots$ & $\ldots$ & $\ldots$ \\
RAINC & 0.23 & 0.21 & 0.22 & $\ldots$ & $\ldots$ & $\ldots$ \\
TMIN & -0.39 & -0.30 & -0.26 & -0.36 & $\ldots$ & $\ldots$ \\
TMAX & -0.26 & -0.20 & -0.27 & -0.20 & 0.28 & $\ldots$ \\
DON & 0.57 & 0.47 & 0.40 & 0.42 & -0.51 & -0.33 \\
\hline
\end{tabular}

a All correlations were statistically significant at $P=0.001$.

${ }^{\mathrm{b}}$ RAINA $=$ no. days of rain $>5 \mathrm{~mm}$ in the 4 -day period from 4 to 7 days prior to wheat head emergence; RAINA $^{2}=$ RAINA squared; RAINB $=$ no. days of rain $>3 \mathrm{~mm}$ in the 4-day period from 3 to 6 days after wheat head emergence; RAINC $=$ no. days of rain $>3 \mathrm{~mm}$ in the 4-day period 7 to 10 days after head emergence; TMIN $=$ no. days of daily minimum temperature $<10^{\circ} \mathrm{C}$ in the 4-day period before wheat head emergence; TMAX $=$ no. days of daily maximum temperature $>32^{\circ} \mathrm{C}$ in the 4-day period 3 to 6 days after wheat head emergence; DON = concentration of deoxynivanol (transformed; $\ln (x+0.1)$ ).
Model validation in 2000. Different
weather conditions were recorded in each of the five field location-centers (Table 4). For example, no rain $>5 \mathrm{~mm}$ occurred in 7 days before heading (i.e., RAINA $=0$ ), while London had $>5 \mathrm{~mm}$ of rain on 2 of 4 days in the period before heading (i.e., RAINA = 2). In the period 3 to 6 days after

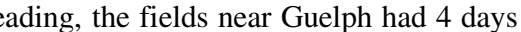
during rain, while no rain occurred Minimum temperatures $<10^{\circ} \mathrm{C}$ occurred on at least 1 day during the period before heading in all fields (Table 4). Temperaon any field from 3 to 10 days after heading in 2000 .

Concentrations of DON varied from 0.2 to $11.5 \mu \mathrm{g} \mathrm{g}^{-1}$ across field locations that were used for validating the model. A chiconcest on the actual and predicted predictions were not by chance alone $\left(\chi^{2}=\right.$ 18.7; $0.25>P>0.15)$. Predictions of the concentration of DON were better in fields where $<1.0 \mu \mathrm{g} \mathrm{g}^{-1}$ occurred. The model
successfully predicted a concentration of $<1.0 \mu \mathrm{g} \mathrm{g}^{-1}$ on five of six fields where the concentration of DON was $<1.0 \mu \mathrm{g} \mathrm{g}^{-1} ; 1.3$ $\mu \mathrm{g} \mathrm{g}^{-1}$ was measured on the one field (Table 4; Sarnia Field 3) that predicted $1.3 \mu \mathrm{g}$
$\mathrm{g}^{-1}$. Overall, the model predicted DON within $1.0 \mu \mathrm{g} \mathrm{g}^{-1}$ on 13 of 17 fields, and within $2.0 \mu \mathrm{g} \mathrm{g}^{-1}$ on 15 of the 17 fields. The three fields near Guelph had the greatest difference between predicted and actual two of these fields had the highest concen-
twon $6.2 \mu \mathrm{g}^{-1}$ ), tration of DON of the 17 fields in the validation study.

\section{ISCUSSION}

Empirical relationships were identified weather variables in three periods around wheat heading; these were used to developed a predictive model. An early predicoped using only rain and temperature information from the period 4 to 7 days 
before heading. The full predictive model, however, used rain and temperature information from three periods between 7 days before heading and 10 days after heading. These results support the hypothesis that concentration of DON in mature grain is highly associated with environmental factors that influence both inoculum production and infection in wheat at heading. While others have reported that the devel- opment of FHB in wheat is highly dependent on weather during the month of anthesis $(16,29)$, our analysis showed that DON may be predicted using weather data from relatively narrow time periods around

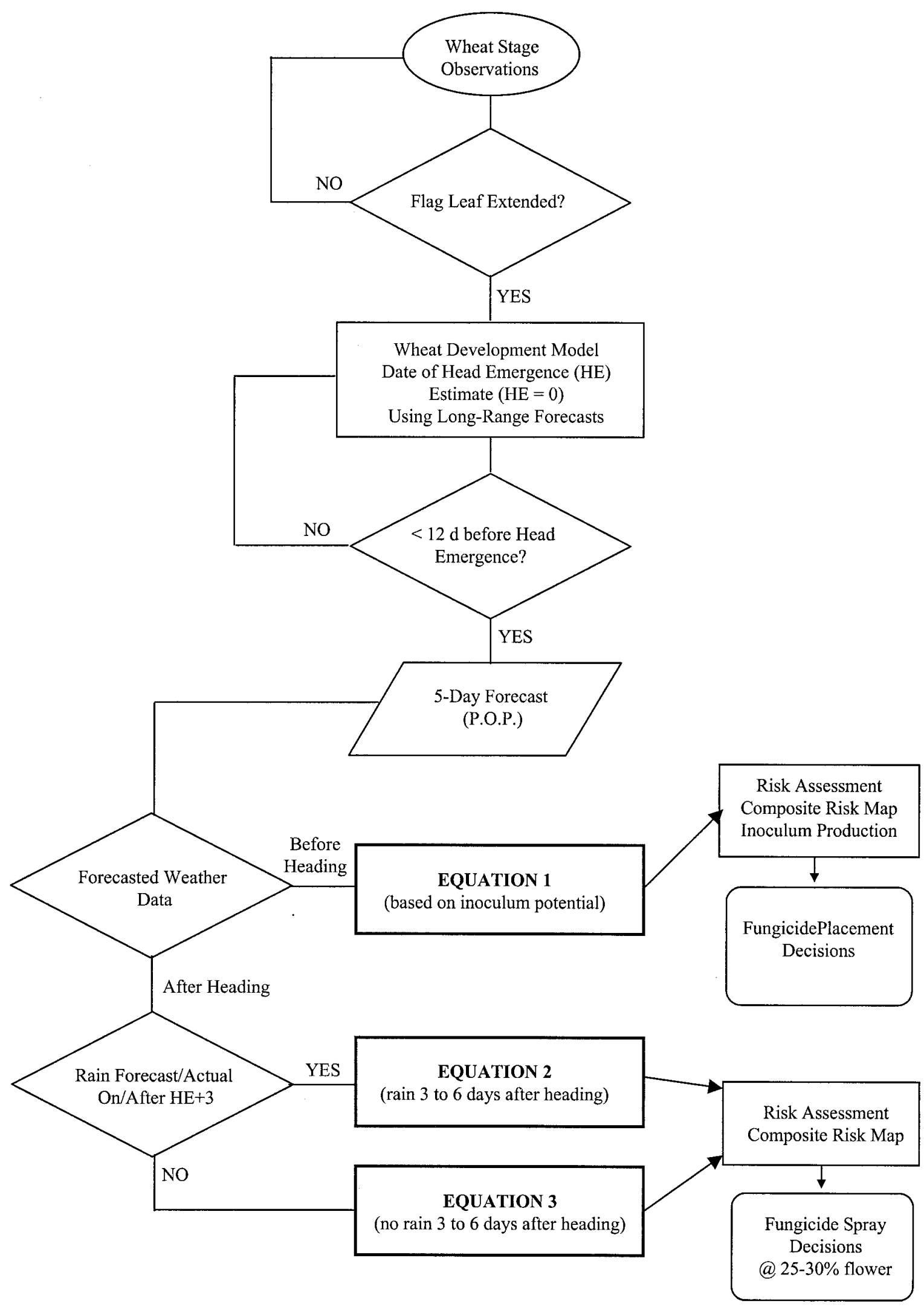

Fig. 2. Flowchart for implementing the weather-based model at heading to predict the concentration of deoxynivalenol (DON) at grain harvest. 
heading. Overall, $73 \%$ of the variability of DON in the field surveys was explained by the model. The model was also supported in the validation study, where both actual and predicted concentrations were $<2.0 \mu \mathrm{g}$ $\mathrm{g}^{-1}$ on 15 of 17 fields. The predictive ability of the model may be attributed, in part, to the diverse weather conditions and array of cultural practices on farm fields in the data set used to develop the model.

The strength of the predictive ability of the model may also be attributed to negli- gible multicollinearity among predictor variables. Independent variables of the prediction equations were only weakly correlated with each other $(r<0.38)$, while

VIF values for most independent variables in the model were close to 1.0. These statistics suggest that each weather variable contributed unique information for predicting the dependent variable (DON) (6). It should be noted that a relationship between RAINA and RAINA ${ }^{2}$ was expected (VIFs >7.1; Table 2) because, by definition, they

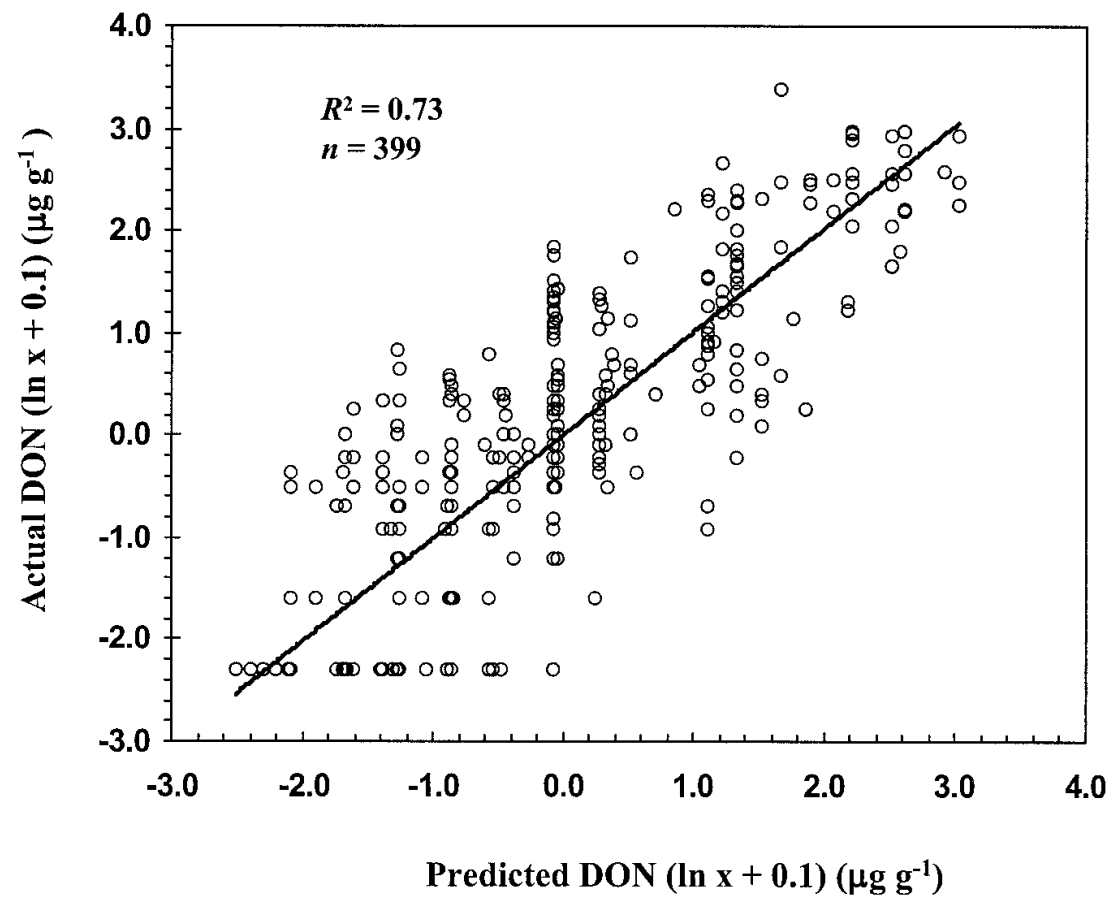

Fig. 3. Actual versus predicted deoxynivalenol (DON) concentrations for all surveyed fields using weather variables from 7 days before heading to 10 days after heading (composite predictions using equations 2 and 3 ). are related to one another. The quadratic variable was retained in the best model, however, because it increased the $R^{2}$, lowered the PRESS statistics (i.e., indicates better predictability), and lowered the overall mean square error $(s)$.

In the first period 4 to 7 days before heading, concentrations of DON increased with 1 or 2 days of rain $>5 \mathrm{~mm}$ and decreased with temperatures $<10^{\circ} \mathrm{C}$. Warm and moist conditions during the 4- and 7day period before heading probably enhanced conditions for both perithecial and ascospore formation and maturation of ascospores. The supply of inoculum is a critical factor in FHB epidemics (22). Francl et al. (14) reported inoculum up to 20 CFU during FHB epidemics compared with levels of 1 to $2 \mathrm{CFU}$ during nonepidemic levels of the disease. Others have associated dry weather with low levels of inoculum $(11,14,21)$. Although we found a relationship between rain and DON across diverse environments on 399 fields, inoculum levels were not measured during these critical periods. Others, however, have attempted to investigate the effects of environment on inoculum levels using only a few fields $(14,21)$. Despite these intense studies, the temporal relationship of rainfall and temperature on levels of inoculum has been difficult to quantify for predicting the potential of epidemics (14). One study showed a peak ascospore release 2 to 4 days after major rainfall (23). Another study showed the incidence of FHB increased with rain 3 to 9 days before anthesis (approximately 2 to 7 days before heading) in three fields (11), and another study showed peak inoculum levels 5 to 7 days after a rain (21). In most cases, when the timing of peak ascospore release coincided with favorable conditions for infection at

Table 4. Validation of model to predict concentrations of deoxynivalenol (DON) in wheat fields across southern Ontario in 2000

\begin{tabular}{|c|c|c|c|c|c|c|c|c|}
\hline \multirow[b]{2}{*}{ Location area } & \multirow[b]{2}{*}{ Field no. } & \multicolumn{3}{|c|}{ Days matching rainfall criteria $^{a}$} & \multicolumn{2}{|c|}{$\begin{array}{c}\text { Days matching } \\
\text { temperature criteria }^{\mathbf{b}}\end{array}$} & \multicolumn{2}{|c|}{$\begin{array}{c}\begin{array}{c}\text { Concentration of DON } \\
\left(\mu \mathrm{g} \mathrm{g}^{-1}\right)^{\mathrm{c}}\end{array} \\
\end{array}$} \\
\hline & & RAINA & RAINB & RAINC & TMIN & TMAX & Actual & Predicted \\
\hline \multirow[t]{4}{*}{ Windsor } & 1 & 0 & 1 & 1 & 3 & 0 & 0.2 & 0.2 \\
\hline & 2 & 0 & 1 & 1 & 3 & 0 & 0.6 & 0.2 \\
\hline & 3 & 0 & 1 & 1 & 3 & 0 & 0.7 & 0.2 \\
\hline & 4 & 0 & 1 & 1 & 3 & 0 & 1.0 & 0.2 \\
\hline \multirow[t]{3}{*}{ Sarnia } & 1 & 1 & 0 & 1 & 1 & 0 & 0.5 & 0.9 \\
\hline & 2 & 1 & 0 & 1 & 1 & 0 & 0.3 & 0.9 \\
\hline & 3 & 1 & 0 & 1 & 1 & 0 & 1.3 & 0.9 \\
\hline \multirow[t]{3}{*}{ Guelph } & 1 & 0 & 4 & 2 & 2 & 0 & 2.1 & 5.3 \\
\hline & 2 & 0 & 4 & 2 & 2 & 0 & 3.6 & 5.3 \\
\hline & 3 & 0 & 4 & 2 & 2 & 0 & 11.5 & 5.3 \\
\hline \multirow[t]{3}{*}{ St. Catherines } & 1 & 1 & 1 & 2 & 3 & 0 & 1.8 & 1.5 \\
\hline & 2 & 1 & 1 & 2 & 3 & 0 & 2.0 & 1.5 \\
\hline & 3 & 1 & 1 & 2 & 3 & 0 & 1.1 & 1.5 \\
\hline \multirow[t]{4}{*}{ London } & 1 & 2 & 0 & 1 & 2 & 0 & 2.6 & 1.3 \\
\hline & 2 & 2 & 0 & 1 & 2 & 0 & 1.3 & 1.3 \\
\hline & 3 & 2 & 0 & 1 & 2 & 0 & 2.1 & 1.3 \\
\hline & 4 & 2 & 0 & 1 & 2 & 0 & 0.7 & 1.3 \\
\hline
\end{tabular}

${ }^{a}$ Number of rain events $\left(>5 \mathrm{~mm} \mathrm{day}^{-1}\right)$ between 4 and 7 days before wheat head emergence (RAINA), or no. of rain events $\left(>3 \mathrm{~mm} \mathrm{day}^{-1}\right)$ between 3 and 6 days (RAINB) or 7 and 10 days (RAINC) after wheat head emergence.

${ }^{\mathrm{b}}$ Number of days of minimum daily air temperature $<10^{\circ} \mathrm{C}$ between 4 and 7 days before wheat head emergence (TMIN), and no. of days of maximum daily air temperature $>32^{\circ} \mathrm{C}$ between 3 and 6 days after wheat head emergence (TMAX).

${ }^{c}$ Actual and predicted concentrations of DON from 17 wheat grain samples hand-harvested at maturity. 
anthesis, a higher incidence of FHB occurred.

During this first period (4 to 7 days before heading), levels of inoculum may be reduced with excessive rain. The quadratic relationship between rain (4 and 7 days before heading) and DON suggests a maximum concentration of DON with 2 days of rain, then a decrease with at least 3 days of rain. Others have suggested that excessive rainfall may inhibit the development of perithecia, impede the release and dissemination of spores, or wash spores off wheat heads (23). None of the fields in our study received 4 days of rain $>5 \mathrm{~mm}$ during this period. Therefore, this relationship between DON and excessive rainfall is not definitive; the hypothesis of a quadratic relationship between rain and DON would have been better tested if 4 days of rain had occurred in the study.

Again, during this first period before heading, daily temperatures $<10^{\circ} \mathrm{C}$ had a negative impact on DON, even though moisture conditions were optimal for DON production. Low temperatures likely delayed or reduced ascospore production during this period, which reduced the levels of inoculum during critical wheat development periods for infection. Other researchers have associated low levels of inoculum with low temperature $(1,11,21)$. De Wolf et al. (11) suggested that a relatively low level of inoculum at one of their sites was attributed to average daily temperatures of approximately $10^{\circ} \mathrm{C}$, because high levels of inoculum were produced at other sites with similar rainfall, but in warmer conditions.

The second period when weather influenced DON occurred between 3 and 6 days after heading. Elevated concentrations of DON in mature grain with rain 3 to 6 days after heading suggests that infection occurred in a relatively narrow period of time after heading. A similar narrow time period was found in one other small field plot study, where maximum infection of wheat heads by $F$. culmorum was associated with wet conditions that were generated using a misting apparatus in a 3-day period around anthesis (17). Although our study did not investigate the effect of weather on infection by various Fusarium species, we did find that the level of contamination of DON was also related to weather during relatively narrow periods around heading or anthesis. Our knowledge of the infection process suggests that there is usually little concern of excessive DON in grain with dry conditions during anthesis. This provided the rationale to separate the data into fields that received rain during the period 3 to 6 days after heading and fields that were dry during this period.

During the second period, 3 to 6 days after heading, DON was elevated with daily rainfall $>3 \mathrm{~mm}$, while temperatures $>32^{\circ} \mathrm{C}$ had a negative impact on DON. The highest concentrations of DON that were measured in this study were in the epidemic year of 1996, which was the year of consistent day-to-day rainfall in most fields around heading (Fig. 1). In addition to the rain, air temperatures did not exceed $32^{\circ} \mathrm{C}$ on any field 3 to 6 days after heading. In 1999 , temperatures exceeded $32^{\circ} \mathrm{C}$ in over $90 \%$ of the fields between 3 and 6 days after heading (Fig. 1). On those fields that exceeded $32^{\circ} \mathrm{C}$ in 1999 , concentrations of DON averaged $0.31 \mu \mathrm{g} \mathrm{g}^{-1}$ compared with $1.30 \mu \mathrm{g} \mathrm{g}^{-1}$ in other fields where lower temperatures occurred around heading (i.e., anthesis) (data not shown). The effects of year on concentrations of DON in this study (Table 1) are likely at least partially associated with temperatures exceeding $32^{\circ} \mathrm{C}$ during the period 3 to 6 days after heading (i.e., approximately anthesis) in some years more than others. Temperatures exceeding $30^{\circ} \mathrm{C}$ have been observed to reduce the growth of $F$. graminearum $(20,24,25)$. The negative effect of daily temperatures exceeding $32^{\circ} \mathrm{C}$ was only important for predicting DON when rain occurred during the period of infection (i.e., rain between day 3 and 6 in equation 2). In other words, high temperatures were not important for predicting DON when conditions were dry during the 3- to 6-day period after heading. This suggests that the potential for infection was at a minimum because of dry conditions.

In the third critical period, 7 to 10 days after heading, rain was the only weather variable to influence DON. We speculate that higher concentration of DON with rain 7 to 10 days after heading (RAINC) in equations 2 and 3 was the result of conditions favorable for the colonization of Fusarium in wheat heads that were infected in the 3- to 6-day period after heading. However, because dry conditions occurred in some fields during the 3- to 6-day period (i.e., those fields in equation 3 ), some of the rain effect in the 7- to 10-day period may have favored infection in the later developing wheat heads in the canopy, rather than colonization or growth of the fungi. The utility of using the variable of rain 7 to 10 days after heading for predicting DON at heading is difficult to assess because of problems associated with accuracy of long-range forecasts. The variable of rain 7 to 10 days after heading accounted for less than $8 \%$ of the total variability explained by the prediction equations. Thus, other weather variables were more useful for predicting DON than the variable of rain 7 to 10 days after heading.

It is important to consider limitations in the data used to develop the model when making predictions in a field. It is well known that factors other than weather influence DON (7,26). Variation among wheat cultivars alone explained $27 \%$ of the variation of DON across these surveyed fields in 1996 to 1999 (26). Although a differential response to wheat cultivar is usually more pronounced in the presence of moderate to high disease pressure (32), white wheat cultivars were contaminated with nearly double the DON compared with red wheat cultivars in the survey (26). Wheat cultivar should be considered as a factor influencing DON (3). The predictive ability of our model would likely be improved if significant factors other than weather were quantified.

Crop rotation may also affect the concentration of DON in fields. It is well known that potentially high concentrations of DON may be expected in wheat planted after corn because of high inoculum potential (31). In this study, less than $9 \%$ of the wheat fields surveyed followed corn in the rotation. Therefore, because less than 9\% of the data used to develop the model are from fields where wheat was planted after corn, the model is likely biased against elevated concentrations of DON in fields where wheat was planted after corn. These differences may explain higher variability of predictions, especially in fields with concentrations of DON $>2 \mu \mathrm{g} \mathrm{g}^{-1}$.

The model may also be improved with a more accurate estimate of a heading date for each field, although we are confident that the actual heading date that was estimated for each field was within a day or two of the actual heading date. Agronomic practices such as cultivar, tillage system, and planting date may have affected the time of heading from field-to-field. Actual heading dates of fields in the survey had to be estimated because the fields were chosen and sampled near harvest. Despite possible errors in heading date (and consequently weather) for each field, the 4-day window in the equations provided some margin for error. The heading date may have been predicted better by choosing and observing the surveyed fields before heading.

This predictive model may be useful for decision-making purposes for the use of fungicides. There are many factors which influence decisions for economical control using fungicides, including the price of the crop, market destinations, the costs associated with fungicide application, and the yield potential of the field. A fungicide application that reduces extremely high concentrations of DON to concentrations insufficient to improve the grade of wheat may not be justified; however, the use of fungicides may be warranted to improve the grade and marketability with predictions of DON at 1 to $2 \mu \mathrm{g} \mathrm{g}^{-1}$. This means that the model may be useful because predictions appear to be better when low to moderate DON concentrations occur $(<2.0$ $\left.\mu \mathrm{g} \mathrm{g}^{-1}\right)$. Poor predictions of DON levels in epidemic situations were expected because when data were log-transformed, any errors were also log-transformed (28). With further validation using actual and forecasted weather data, the model can at least be used to alert the wheat industry to prepare to deal with severe DON problems. 


\section{ACKNOWLEDGMENTS}

We thank Diane Paul and Todd Phibbs of Ridgetown College, University of Guelph, for their dedication to this project in both the field and the laboratory. Jennifer Winter obtained weather information from Environment Canada. O. Brian Allen and Geoff Smale of the Ashton Statistical Consulting Laboratory, University of Guelph, assisted and recommend some of the statistically sound analytical procedures used in this paper. Funding was made through the Grow Ontario Program and Agricultural Adaptation Council (AAC) CanAdapt program, in partnership with the Ontario Wheat Producers' Marketing Board, Pioneer Hi-Bred Canada Ltd., Syngenta Seeds Ltd., Bayer Canada Ltd., Aventis Ltd., Monsanto Canada Ltd., Ontario Seed Growers Association, Dow AgroSciences Ltd., W. G. Thompson and Sons Ltd., C \& M Seeds Ltd., First Line Seeds Ltd., Gustafson Canada Ltd., and lastly with the University of Guelph under contract with the Ontario Ministry of Agriculture, Food and Rural Affairs.

\section{LITERATURE CITED}

1. Andries, C., Jarosz, A., and Trail, F. 2000. Effects of rainfall and temperature on production of perithecia by Gibberella zeae in field debris in Michigan. Pages 118-119 in: Proc. 2000 National Fusarium Head Blight Forum, Erlanger, KY.

2. Asher, M. J. C., and Williams, G. E. 1991. Forecasting the national incidence of sugarbeet powdery mildew from weather data in Britain. Plant Pathol. 40:100-107.

3. Bai, G. H., and Shaner, G. 1994. Scab of wheat: Prospects for control. Plant Dis. 78:760-766.

4. Bom, M., and Boland, G. J. 2000. Evaluation of disease forecasting variables for sclerotinia stem rot (Sclerotinia sclerotiorum) of canola. Can. J. Plant Sci. 80:889-898.

5. Boote, K. J., Jones, J. W., Pickering, N. B. 1996. Potential uses and limitations of crop models. Agron. J. 88:704-716.

6. Bowerman, B. L., and O'Connell, R. T. 1990. Linear Statistical Models: An Applied Approach, 2nd ed. Duxbury Thomson Learning, Pacific Grove, CA.

7. Clear, R. M., and Abramson, D. 1986. Occurrence of Fusarium head blight and deoxynivalenol in two samples of Manitoba wheat in 1994. Can. Plant Dis. Surv. 66:9-11.

8. Clear, R. M., and Patrick, S. K. 1990. Fusarium species isolated from wheat samples containing tombstone (scab) kernels from Ontario, Manitoba, and Saskatchewan. Can. J. Plant Sci. 70:1057-1069.

9. Coakley, S. M., McDaniel, L. R., and Shaner, G. 1985. Model for predicting severity of
Septoria tritici blotch on winter wheat. Phytopathology 75:1245-1251.

10. Cook, R. J., and Christen, A. A. 1976. Growth of cereal root rot fungi as affected by temperature-water potential interactions. Phytopathology 66:193-197.

11. De Wolf, E., Francl, L., Lipps, P., Madden, L., Osborne, L., and Jin, Y. 2000. Factors affecting the development of wheat Fusarium head blight. Pages 137-140 in: Proc. 2000 National Fusarium Head Blight Forum, Erlanger, KY.

12. Falk, D. E., Hunt, L. A., Meatherall, G., and Szlavnics, Z. 2000. Barley, Oats and Wheat, Ontario Performance Trials Progress Report. Department of Plant Agriculture, University of Guelph, Guelph, Ontario, Canada.

13. Fernando, W. G. D., Paulitz, T. C., Seaman, W. L., Dutilleul, P., and Miller, J. D. 1997. Head blight gradients caused by Gibberella zeae from area sources of inoculum in wheat field plots. Phytopathology 87:414-421.

14. Francl, L., Shaner, G., Bergstrom, G., Gilbert, J., Pedersen, W., Dill-Macky, R., Sweets, L., Corwin, B., Jin, Y., Gallenberg, D., and Weirsma, J. 1999. Daily inoculum levels of Gibberella zeae on wheat spikes. Plant Dis. 83:662-666.

15. Hall, R., and Sutton, J. C. 1998. Relation of weather, crop, and soil variables to the prevalence, incidence, and severity of basal infections of winter wheat in Ontario. Can. J. Plant Pathol. 20:69-80.

16. Inglis, D. A., and Cook, R. J. 1981. Calonectria nivalis causes scab in the Pacific Northwest. Plant Dis. 67:827-828.

17. Lacey, J., Bateman, G. L., and Mirocha, C. J. 1999. Effects of infection time and moisture on development of ear blight and deoxynivalenol production by Fusarium spp. in wheat. Ann. Appl. Biol. 134:277-283.

18. Miller, J. D. 1994. Epidemiology of Fusarium ear diseases of cereals. Pages 19-39 in: Mycotoxins in grain: Compounds other than aflatoxin. J. D. Miller and H. L. Trenholm, eds. Eagan Press, St. Paul, MN.

19. Miller, J. D., Culley, J., Fraser, K., Hubbard, S., Meloche, F., Ouellet, T., Seaman, L., Seifert, K. A., Turkington, K., and Voldeng, H. 1998. Effect of tillage practice on Fusarium head blight of wheat. Can. J. Plant Pathol. 20:95-103.

20. Moschini, R. C., and Fortugno, C. 1996. Predicting wheat head blight incidence using models based on meteorological factors in Pergamino, Argentina. Eur. J. Plant Pathol. 102:211-218.

21. Osborne, L., Jin, Y., and Kohl, R. 2000. Fusarium head blight: Inoculum detection, disease progress, and environmental influences. Pages
163-168 in: Proc. 2000 National Fusarium Head Blight Forum, Erlanger, KY.

22. Parry, D. W., Jenkinson, P., and McLeod, L. 1995. Fusarium ear blight (scab) in small grain cereals-a review. Plant Pathol. 44:207 238.

23. Paulitz, T. C. 1996. Diurnal release of ascospores by Gibberella zeae in inoculated wheat plots. Plant Dis. 80:674-678.

24. Pugh, G. W., Johann, H., and Dickson, J. G. 1933. Factors affecting infection of wheat heads by Gibberella saubinetii. J. Agric. Res. 46:771-797.

25. Reid, L. M., Nicol, R. W., Ouellet, T., Savard, M., Miller, J. D., Young, J. C., Stewart, D. W., and Schaafsma, A. W. 1999. Interaction of Fusarium graminearum and $F$. moniliforme in maize ears: Disease progress, fungal biomass, and mycotoxin accumulation. Phytopathology 89:1028-1037.

26. Schaafsma, A. W., Tamburic-Ilincic, L. Miller, J. D., and Hooker, D. C. 2001. Agronomic considerations for reducing deoxynivalenol in wheat grain. Can. J. Plant Pathol. 23:279-285.

27. Sinha, R. C., and Savard, M. E. 1996. Comparison of immunoassay and gas chromatography methods for the detection of the mycotoxin deoxynivalenol in grain samples. Can. J. Plant Pathol. 18:233-236.

28. Smith, J. L., Schnabel, R. R., McNeal, B. L. and Campbell, G. S. 1980. Potential errors in the first-order model for estimating soil nitrogen mineralization potentials. Soil Sci. Soc. Am. J. 44:996-1000.

29. Snijders, C. H. A. 1990. Fusarium head blight and mycotoxin contamination of wheat: A review. Neth. J. Plant Pathol. 96:187-198.

30. Spring, K. 1998. Chicago Board of Trade quality requirements for wheat contract approved by CFTC. Chicago Board of Trade Press Release. November 24, 1990 CBOT.com.

31. Sutton, J. C. 1982. Epidemiology of wheat head blight and maize ear rot caused by Fusarium graminearum. Can. J. Plant Pathol. 4:195-209.

32. Wiersma, J. V., Peters, E. L., Hanson, M. A. Bouvette, R. J., and Busch, R. H. 1996. Fusarium head blight in hard red spring wheat: Cultivar responses to natural epidemics. Agron. J. 88:223-230.

33. Workneh, F., Yang, X. B., and Tylka, G. L. 1999. Soybean brown stem rot, Phytophthora sojae, and Heterodera glycines affected by soil texture and tillage relations. Phytopathology 89:844-850.

34. Zadoks, J. C., Chang, T. T., and Konzak, C. F. 1974. A decimal code for the growth stages of cereals. Weed Res. 14:415-421. 